\title{
El tópico de "los orígenes ideológicos" de las revoluciones de independencia como problema. Una relectura a partir de Tradición política española e ideología revolucionaria de Mayo, de Tulio Halperin Donghi
}

The question of "the ideological origins" of independence revolutions as an issue. A rereading through Tradición politica española e ideología revolucionaria de mayo, by Tulio Halperin Donghi

\section{Elías J. Palti}

\section{RESUMEN}

Uno de los temas centrales en la historia de ideas en América Latina es el de los orígenes ideológicos de las revoluciones de independencia. La cuestión ha dado lugar a largas disputas en cuanto a la filiación de las ideas que permitieron la emergencia del discurso revolucionario. Según se intenta mostrar en este ensayo a partir de una relectura de Tradición política española e ideología revolucionaria de Mayo, de Tulio Halperin Donghi, ese afán por determinar cuáles fueron las ideas precursoras del discurso revolucionario resulta inconducente, dado que no hay forma de establecer cuál es el origen preciso de una idea particular. $Y$ aun en caso de poder hacerlo, resulta irrelevante para comprender la naturaleza de ese discurso. De lo que se trata, en cambio, es de entender cómo esas ideas, sea cual fuere su origen, se rearticularon en función de problemáticas ya completamente diversas de aquellas a partir de las cuales surgieron. En el presente trabajo se hace un esbozo de la serie de torsiones que fueron experimentando los conceptos clave del pensamiento tradicional hispano y de cómo ésas terminarían abriendo las puertas a la emergencia de un tipo de discurso que escaparía ya de sus marcos.

\section{PALABRAS CLAVE}

Historia intelectual; Revoluciones de independencia; América Latina.

\section{ABSTRACT}

One of the central topics in the Latin American history of ideas is that of the ideological origins of the independence revolutions. This issue has led to a series of disputes regarding the filiation of the ideas that supported the emergence of the revolutionary discourse. Through a rereading of Halperin Donghi's Tradición política española e ideología revolucionaria de Mayo, this paper intends to show that the urge to establish the precursory ideas of the revolutionary discourse is misleading since there is no way of knowing the precise origin of a particular idea. Furthermore, in case it were possible, it would be irrelevant to understand the nature of that discourse. Instead, the point is to understand how those ideas, whatever their origin, became rearticulated in connection with problems that were completely different to those from which the ideas at stake emerged. The present paper outlines the series of transformations that the key concepts of traditional Hispanic thinking went through and how they opened the doors for the unfolding of a type of discourse that distanced itself from the frameworks of that thinking.

\section{KEYWORDS}

Intellectual history; Independence revolutions; Latin America. 
La cuestión de los orígenes ideológicos de las revoluciones de independencia latinoamericanas recorre centralmente la vieja tradición historiográfica liberal-nacionalista. Ésta interpreta dichas revoluciones como el resultado del arribo de los ideales ilustrados de libertad, provenientes mayormente de Francia, los cuales habrían despertado en la población criolla el afán de independencia, dando así, finalmente, lugar a la manifestación de una voluntad nacional por largo tiempo silenciada y sometida a un poder extraño.

En realidad, esa interpretación tradicional sólo habrá de recoger, en lo esencial, el punto de vista de los propios actores de la revolución, que imaginaban que su revuelta establecía un corte radical respecto de la tradición precedente, una aurora de la libertad que, para ser tal, debía estar libre de toda mácula colonial. La exploración de los lazos que unían las ideas que sirvieron de fundamento ideológico a la revolución a la tradición política hispana quedaría así como una tarea reservada, casi por definición, a las corrientes hispanófilas de raíces católicas. Contrariamente a lo que sostiene la perspectiva liberalnacionalista, los fundamentos ideológicos de las revoluciones de independencia le deberían menos a las doctrinas ilustradas francesas que a un ideal pactista de larga tradición en el pensamiento hispano, cuyos orígenes se remontarían a las filosofías neoescolásticas del siglo XVII, cuyo principal representante fue el jesuita Francisco Suárez.

En el Río de la Plata, quien propugnó más enfáticamente esa tesis en el siglo XX fue un historiador, también jesuita, Guillermo Furlong (1952). En su momento, la tesis no tuvo mayor aceptación más allá de los estrechos círculos de pensamiento histórico vinculados a la Iglesia católica. Sin embargo, las tendencias más recientes, llamadas "revisionistas" y surgidas en torno del Bicentenario, retomarían ese motivo, reabriendo el debate en torno del tópico.

Según afirman los autores enrolados en esa corriente "revisionista" reciente, cuyo principal representante es FrançoisXavier Guerra, en las colonias hispanoamericanas, los patrones 
coloniales permanecerían inconmovibles a las perturbaciones de orden puramente político traídas por la revolución de independencia. Aun luego de producida ésta, los patrones mentales y las matrices de pensamiento tradicional heredados seguirían siendo los dominantes (GUERRA 1992). Las colonias ultramarinas no recibirían el impulso renovador, en el plano ideológico, que sí conmovió a la península durante el proceso abierto por la vacancia real tras las abdicaciones de Bayona y que llevaría a la sanción, en 1812, de la constitución liberal, la llamada "Constitución de Cádiz".

Esa corriente revisionista reciente, si bien retoma un motivo propio de la antigua tradición de pensamiento histórico de matriz católico-conservadora, se aparta de esta en un punto crucial: ya no habrá de enfatizar los vínculos entre los movimientos revolucionarios en América Latina y la tradición de pensamiento católico, sino que verá dichos movimientos como resultado de un proceso revolucionario más general que abarcó de conjunto al imperio hispano y que tuvo su epicentro en la propia península. Pero, contrariamente a lo afirmado por las visiones liberales-nacionalistas, ese proceso revolucionario más general, al inscribirse en las colonias en una matriz de pensamiento tradicional, generó contradicciones insalvables que determinarían - y explicarían - el fenómeno de fragmentación territorial y crisis políticas que atravesaría la región a lo largo del siglo posterior a las independencias.

Con ello, esa interpretación termina invirtiendo la perspectiva liberal-nacionalista. Mientras que ésta giró en torno a la oposición entre los ideales liberales de las colonias, que adoptaron las doctrinas ilustradas francesas, y un centro imperial aferrado a su tradición escolástica-feudal, de matriz católica, para las corrientes revisionistas recientes, la oposición se establecerá entre, por un lado, un centro imperial sacudido por el proceso revolucionario iniciado con las abdicaciones de Bayona y la vacancia real, que difunde allí las ideas liberales modernas, y, por otro lado, la persistencia en el mundo colonial de imaginarios tradicionales que permanecerían imperturbables ante ese 
movimiento renovador en el plano ideológico, que abrazaría el centro imperial, pero que no se expandiría más allá de él.

Lo cierto, sin embargo, es que, de ese modo, las interpretaciones revisionistas recientes, si bien sirven para dislocar cierta imagen uniforme del pensamiento hispano que es propia de la perspectiva tradicional liberal-nacionalista (que tiende a ver ese pensamiento como una tradición que se mantiene inmutable a lo largo de los tres siglos que suceden a la Conquista), la inversión de las perspectivas que producen, instalando una nueva antinomia entre el liberalismo hispano y el tradicionalismo de las colonias, lleva a perder de vista aquello que constituye la problemática fundamental que plantea este tipo de fenómenos de ruptura y de la que se ocupa centralmente Halperin Donghi en su obra Tradición política española e ideología revolucionaria de Mayo, publicada originalmente en 1961: cómo nuevos horizontes políticos se desplegarían necesariamente a partir de torsiones producidas en el interior de los marcos conceptuales e instituciones preexistentes, siendo, sin embargo, incompatibles con ellos (HALPERIN DONGHI 2010, p. 25).

En definitiva, la inversión de las perspectivas que produce la escuela revisionista refiere a los contenidos de las perspectivas liberales-nacionalistas tradicionales en América Latina, pero preserva, en lo esencial, la misma metodología, fundada en la antinomia entre "tradición" y "modernidad". Frente a esta visión hoy difundida, más atenta a las continuidades observadas luego de la independencia en el plano de los imaginarios e instituciones, cabe aún el señalamiento con que cierra Halperin Donghi el libro mencionado, el de que la revolución de independencia fue efectivamente una revolución. Como dice el autor:

[buscando la continuidad en el plano de las ideas] corren el peligro de subrayar la afinidad entre el mundo de las ideas revolucionarias y el vigente antes de la revolución, olvidando un hecho más esencial que esa afinidad misma: que -como se ha señalado ya- con esas ideas se estructura una ideología revolucionaria, un instrumento ideológico para negar y condenar todo un pasado (HALPERIN DONGHI 2010, p. 12). 
La eventual persistencia de imaginarios tradicionales no puede oscurecer aún ese hecho abrumador o llevar a desconocer la naturaleza de tal acontecimiento, el quiebre histórico fundamental que entonces tuvo lugar, lo que, a su vez, no supone necesariamente ignorar el hecho de que esa ruptura encontró raíces en ese mismo pasado con el que se quiso romper. Esto nos lleva a la paradoja a partir de la cual se despliega la mencionada obra: el hecho de que "esas ideas [las revolucionarias], que no se justifican por su historia, tienen sin embargo una historia: los principios en cuyo nombre se condena a la realidad prerrevolucionaria han surgido dentro de esa realidad misma" (HALPERIN DONGHI 2010, p. 25). Halperín Donghi se propone así reconstruir cómo fue que se produjo dicha torsión ideológica, cómo horizontes tradicionales de ideas pudieron haber dado lugar a aquello que constituía su misma negación: la ideología revolucionaria.

La definición de esa problemática no sólo lo llevaría a replantear la problemática específica, sino que, para hacerlo, debería apartarse de los marcos propios de la historia de ideas en general. En un artículo recientemente publicado en la revista Prismas, Fernando Devoto señala la distancia que separa ese libro de Halperin Donghi respecto de su anterior obra, dedicada al pensamiento de Esteban Echeverría (HALPERIN DONGHI 1951; DEVOTO 2015, p. 27). Mientras que en ésta se enfoca, básicamente, en tratar de filiar el origen de las ideas de Echeverría, es decir, establecer si eran de matriz iluminista o historicista, en el otro de los libros descubrirá ya hasta qué punto esa empresa genealógica de las ideas resulta totalmente inconducente. La pregunta será ahora no por el origen de las ideas sino por cómo éstas se vieron resignificadas a partir de su reinserción en nuevos campos discursivos ordenados en torno de nuevas problemáticas. Lo que cambiarían, entonces, no serían las ideas sino la lógica de su articulación. Según afirma el este autor:

Si, tal como se ha visto, la originalidad de un pensamiento político reside sólo excepcionalmente en cada una de las ideas que en él se coordinan, buscar la fuente de cada una de ellas parece el camino menos fructífero (a la vez que el menos seguro) para reconstruir la historia de ese pensamiento (HALPERIN DONGHI 2010, p. 35). 
En última instancia, para Halperin Donghi, ambas posturas opuestas respecto de los orígenes ideológicos de la independencia, es decir, tanto aquellas que enfatizan sus raíces tradicionales como las que señalan la modernidad de sus referencias conceptuales, trasuntan un problema menos específico a cada una de ellas que a un tipo de procedimiento intelectual que es propio de toda historia de ideas: el de descomponer las formaciones ideológicas en sus elementos primitivos para luego trazar sus filiaciones intelectuales. Dicho procedimiento lleva, de manera inevitable, a obliterar aquello que identifica a cada una de dichas formaciones ideológicas, que no radica tanto en la naturaleza o el origen de los componentes que recogen como en el modo en que lo van a rearticular en los diversos contextos históricos, sirviendo a propósitos y funciones ya muy diversos a los originarios. La comprensión del proceso ideológico que proveyó el marco conceptual a las revoluciones lleva a Halperín Donghi a elaborar un esquema interpretativo que atraviesa la antinomia entre "ruptura" y "continuidad", entre "tradición" y "modernidad", haciendo manifiestas las graves distorsiones históricas a las que unas y otras tendencias historiográficas opuestas conducen.

\section{La matriz conceptual del absolutismo monárquico}

Según señala Halperin Donghi, quienes insisten en la continuidad entre las ideas pactistas neoescolásticas y aquellas que el discurso revolucionario adopta pierden de vista una diferencia crucial: para el pensamiento absolutista del siglo XVII, resultaba inconcebible la idea de la existencia de una comunidad desprendida de la figura real. Es en el monarca que viene a encarnarse el cuerpo místico de la república. Para el pensamiento del siglo XVII, ninguna comunidad podría constituirse sin un centro de autoridad en torno al cual articularse. Como decía Francisco Suárez (1971, cap. VIII, § 9), "un cuerpo sin cabeza es mutilado y monstruoso". Según señala Halperin Donghi: 
[Para Suárez] la muchedumbre puede ser considerada desde dos puntos de vista diferentes: como un mero agregado, sin orden ni unión física y moral, o como cuerpo político. Ahora bien $-\mathrm{y}$ volvemos a hallar aquí el postulado derivado de una concepción autoritaria de la relación política-, el cuerpo político exige, como una de sus condiciones esenciales, la presencia del poder político (HALPERIN DONGHI 2010, p. 33).

En definitiva, lo que esas interpretaciones pierden de vista es que el pactismo neoescolástico, lejos de ser una ideología precursora de las ideas revolucionarias, era "una pura política del poder" (HALPERIN DONGHI 2010, p. 37).

Lo anteriormente señalado se relaciona, a su vez, con otra diferencia importante que tales interpretaciones necesariamente deben ignorar. Sin bien el concepto pactista neoescolástico imponía ciertos límites al poder real, éstos no estaban relacionados con la necesidad de respetar la voluntad popular, sino con los fines que se encontrarían adheridos a su investidura. La voluntad no tenía fuerza normativa en los marcos del pensamiento del Antiguo Régimen, sólo eran legítimas aquellas normas que resultaban compatibles con los principios eternos de justicia, establecidos por Dios mismo en el plan de la creación. Estas no eran materia de opinión ni se encontraban subordinadas a la voluntad de los sujetos.

La idea de un "contrato social", de hecho, no designaba el carácter voluntarista de la génesis de la sociedad, sino todo lo contrario. En el pensamiento del siglo XVII, contrato y voluntad se excluían mutuamente: si es necesario establecer un contrato es, precisamente, para obligar a los contrayentes a hacer algo que no harían voluntariamente. De lo contrario, el contrato no tendría sentido alguno.

Según la definición entonces utilizada, el contrato social era el recordatorio de que la soberanía le había sido otorgada al monarca no para beneficio propio sino para beneficio de la comunidad. Se ligaba así a la existencia de límites metapositivos a la autoridad real que el propio monarca no podía violar sin convertirse en un tirano. Tales límites estaban dados por lo fines 
adheridos a su función. Es aquí, sin embargo, que encontramos el punto sobre el que pivotaría la primera de las series de torsiones producidas en el interior del universo conceptual del absolutismo monárquico y que, llegado el momento, terminarían abriendo las puertas a la articulación del discurso de la emancipación.

\section{La primera torsión: la secularización de los fines}

La afirmación de un sistema de Estados en el continente tras la Paz de Westfalia (1648) trae aparejadas reformulaciones político-conceptuales fundamentales que introducirán una serie de torsiones en las categorías en cuestión. En primer lugar, la pérdida de los ideales universalistas de los antiguos imperios se traducirá en la redefinición de los fines respecto de la tradición cristiana-medieval, los cuales pierden su carácter trascendente (la realización del reino de Dios en la tierra) y pasan a ser interpretados en un sentido crecientemente profano. "El bien común es ahora definido como la felicitas civitatis y la de los ciudadanos en cuanto tales" (HALPERIN DONGHI 2010, p. 36). La llegada del pensamiento ilustrado habrá, de hecho, de profundizar ese proceso de redefinición político-conceptual; "lo esencial del cambio -dice Halperin Donghi (2010, p. 45) reside en una revalorización de los datos de la experiencia".

La secularización de los fines a los cuales se orienta la comunidad política, lejos de ser un movimiento contradictorio con la monarquía católica, según suele interpretarse, tendía más bien a reforzar el carácter esotérico del poder. Desde el momento en que los principios que regulan la convivencia colectiva pierden su carácter trascendente, la posibilidad de acceder a ellos por parte de los sujetos ya no se reduce a una cuestión puramente ética sino que involucra ciertas capacidades racionales. Ya no se considera que esa ley natural sea algo grabado por Dios mismo en el corazón de los sujetos (que es lo que expresaba el principio de synderesis: la inteligibilidad natural de los principios eternos de justicia), sino algo que 
debe ser adquirido. Dada la naturaleza convencional de esa normatividad positiva, ella escaparía del plano doxológico; su acceso se volvería algo privativo de aquellos que se encontraban en posesión de un cierto saber específico.

Sin embargo, por otro lado, en la península hispana, tal fenómeno se conjugará con una creciente conciencia respecto de la decadencia del sistema imperial, lo que llevará, a su vez, a redescubrir las antiguas libertades. La declinación del orden monárquico se atribuirá, entonces, al apartamiento de la "constitución tradicional" española, lo que dará lugar, a su vez, al surgimiento de la corriente constitucionalista histórica, cuyo principal representante fue Melchor Gaspar de Jovellanos. Tal corriente se dedicará a hurgar en el pasado en busca de esa supuesta constitución tradicional hispana de la que el despotismo se habría apartado. Y ello marca, ahora sí, un quiebre fundamental respecto del pensamiento político absolutista. Encontramos aquí la segunda torsión producida en los marcos del pensamiento absolutista.

\section{La segunda torsión: la distinción de la nación del cuerpo del monarca}

La definición de cuál era esa supuesta constitución tradicional española resultará siempre problemática, puesto que dará lugar a controversias entre las distintas regiones (cada una creerá encontrarla en el momento en que su región particular adquiere mayor preeminencia). ${ }^{1}$ De todos modos, y más allá de las disputas que generó, el surgimiento de la corriente constitucionalista histórica señalaría la emergencia de un nuevo sujeto. La tratadística política se apartará entonces del género tradicional de los espejos del príncipe para orientar su mirada hacia un nuevo objeto: la nación y su pasado, desprendiéndose finalmente del cuerpo del monarca. Como señala, nuevamente, Halperin Donghi (2010, p. 97), "la figura del Rey no se identifica ya para él con la nación toda: ésta se sitúa en una esfera más alta y abarcadora". Y ello quiebra, de hecho, la lógica de la política del Antiguo Régimen, visto que
1 - Uno de los líderes del partido liberal, Agustín Argüelles, señalaría esto durante las sesiones en las Cortes de Cádiz: "No era posible adoptar ninguna regla en este punto sin promover un cisma entre las categorías nobiliarias de León y Castilla. Unas presumían tener preferencia sobre las que sólo eran conocidas por privanza y favor, mientras ellas alegaban siglos de distinción y renombre, reclamando otras contra las que fundasen su derecho gracias a mercedes concedidas por asientos y empresas de ganancia y lucro en épocas de apuro del erario. Si antes de la insurrección habían dormido sus deseos y sus pretensiones, a la par con los del resto de la nación, no se podía prever, después de conmovidos los ánimos, a dónde llegarían sus rivalidades, sus quejas y sus resentimientos, ofendidas con clasificaciones aristocráticas, hechas arbitrariamente ahora, no para arreglar el ceremonial y etiqueta de palacio, sino con el fin de negar o conceder derechos políticos exclusivos, de restablecer una institución extinguida de tres siglos [las Cortes], que si había de resucitar era preciso que renaciese bajo otra forma y con diversos atributos de los que tenía al expirar en el siglo XVI 
"Patria y nación son nociones que innovan radicalmente sobre el pensamiento político tradicional, en la medida en que se ven de modo cada vez más decidido como entidades que son capaces de subsistir al margen de las organizaciones estatales" (HALPERIN DONGHI 2010, p. 100).

Lo cierto es que esa nación, desprendida ya del cuerpo del monarca, pronto encontrará también sus órganos de expresión colocados al margen del aparato del Estado absolutista. En efecto, en su lucha contra los intentos de centralización política por parte de los Borbones, las corporaciones urbanas comenzarán a invocar la autoridad del pueblo y de la nación, erigiéndose, así, en sus voceros. La paradoja aquí es que la propia monarquía invocaría también a la nación y al pueblo tanto en luchas contra enemigos externos como en su enfrentamiento con las oligarquías urbanas. Llegado el momento, esa nación, ya desgajada del aparato de Estado real y politizada por propia acción de la monarquía, se enfrontará a ese mismo Estado al que habrá de declarar artificial. $Y$ es aquí que encontramos la tercera de las series de torsiones producidas en el interior de los marcos conceptuales del Antiguo Régimen que observa Halperin Donghi.

\section{La tercera torsión: el surgimiento del poder constituyente}

La estructura del discurso del primer liberalismo español se apoyará en el propio concepto pactista tradicional, pero introducirá en él un elemento que le era heterogéneo y que alterará profundamente su sentido. Dicho discurso instala una antinomia antes inexistente: todo él se sostiene en la oposición entre, por un lado, la nación, que, en tanto fundamento natural, desplaza de ese sitial al poder real, y, por otro lado, el Estado, postulado como un armazón político artificial. Así, se vuelve imaginable, para ellos, la oposición entre una sociedad natural que existe con independencia de la investidura real y esta última, la cual encarnaría un tipo de autoridad puramente convencional. Llegado a este punto, Francisco Martínez Marina podrá afirmar: 
La autoridad paterna y el gobierno patriarcal, el primero sin duda y único que por espacio de muchos siglos existió entre los hombres, no tiene semejanza ni conexión con la autoridad política, ni con la monarquía absoluta, ni con alguna de las formas legítimas de gobierno adoptadas por las naciones en diferentes edades y tiempos. [...] La autoridad paterna bajo la primera consideración proviene de la naturaleza, precede a toda convención, es independiente de todo pacto, invariable, incomunicable, imprescriptible: circunstancias que de ninguna manera convienen ni son aplicables á la autoridad política, y menos la monarquía absoluta. Este género de gobierno le introdujo el tiempo, la necesidad y el libre consentimiento de Ios hombres: es variable en sus formas y sujeto á mil vicisitudes (MARTÍNEZ MARINA 1988, p. 92-93).

Esto, como vimos, disloca la lógica del poder del Antiguo Régimen en la medida en que instala la presencia de dos soberanías contradictorias (la real y la nacional) en un mismo plano de realidad. Su confrontación resultaba ya inevitable, pues ambas no podían coexistir en un mismo plano; una necesariamente debería subordinar a la otra.

Sin embargo, la definición de ese nuevo sujeto - la nación soberana - daría lugar a la emergencia de una serie de interrogantes acerca de su entidad y su origen ya nada sencillos de resolver. Básicamente, perdida la idea de un agente trascendente que le sirviera de fundamento - como lo era la autoridad real -, la pregunta que surgiría sería la de cómo la nación podría constituirse a sí misma. Sin embargo, llegados a este punto, encontramos aquel límite inherente a ese primer liberalismo hispano: esa cuestión aún no habrá de plantearse en él como un problema. La vacancia real producida tras las abdicaciones de Bayona y la ocupación de la península por parte de una fuerza militar extranjera hacen que emerja la cuestión nacional. Sin embargo, la existencia de la nación hispana se la daría simplemente por supuesta y el propio alzamiento espontáneo de la población local contra el ocupante extranjero parecía dar prueba de ello.

En efecto, según entendían los propios diputados, si bien lo que emerge entonces ya no tiene nada en común con la antiguas 
Cortes, pues se trata, en realidad, de un poder constituyente, ${ }^{2}$ éste, en realidad, tenía por misión instituir únicamente un nuevo régimen de gobierno. Y ello presuponía ya la existencia de ese sujeto que pudiera hacerlo.

Una nación -decía el diputado Juan Nicasio Gallego-, antes de establecer sus leyes constitucionales y adoptar una forma de gobierno es ya una nación, es decir, una asociación de hombres libres que han convenido voluntariamente en componer un cuerpo moral, el cual ha de regirse por leyes que sean el resultado de la voluntad de los individuos que lo forman y cuyo único objeto es el bien y la utilidad de toda la sociedad (ARTOLA 1959, p. 409, cursivas nuestras).

Sólo en las colonias habría de producirse la última torsión en la serie de desplazamientos en los marcos conceptuales propios del absolutismo monárquico que analiza Halperín Donghi.

\section{La cuarta torsión: el problema de la constitución de la nación}

En las posesiones ultramarinas de España habrá de plantearse un problema ya muy distinto. El postulado de que la vacancia real hacía que la soberanía recayera sobre el pueblo no aclaraba aún a qué pueblo se hacía referencia. El gran interrogante que emergería entonces era el relativo a cómo delimitar qué grupos sociales podrían reclamar para sí la posesión de derechos soberanos. Según los defensores del orden colonial, dicho principio se refería al conjunto de los súbditos de la corona y ninguna sección particular podía arrogarse exclusividad. Las poblaciones criollas, en cambio, impugnarían ese criterio, reivindicando el derecho a su autodeterminación. Ahora, el problema que planteaba ese postulado era el de que, en caso de generalizarse, si cada sección de la población proclamara el derecho a su autodeterminación invocando la posesión de una voluntad soberana, eso daría lugar a un proceso de fragmentación política y territorial que no parecía tener un límite posible. De hecho, el principio pactista presuponía un cierto criterio de demarcación (quiénes podrían pactar entre sí y reclamar para sí la posesión derechos soberanos, siendo
2 - Era ya clara, según decía en una sesión el diputado Benito Ramón Hermida, "la esencialísima diferencia de las Cortes pasadas y presentes: aquéllas, limitadas a la esfera de un Congreso Nacional del Soberano, y éstas, elevadas a las de un Soberano Congreso, cuyo nombre corresponde más bien que el equívoco de Cortes" (FERNÁNDEZ MARTÍN 1885, p. 703). 
que está claro que no cualquier grupo humano puede hacerlo) sin nunca poder proveer uno dada la naturaleza abstracta y genérica del sujeto en cuestión.

Más grave aún, sin embargo, sería el hecho de que pronto habría de descubrirse en las colonias que esa nación capaz de reasumir su soberanía en realidad no existía allí. En definitiva, en esas tierras se plantearía la paradoja de tener que constituir, junto con el poder político, al propio sujeto que debía constituir dicho poder. El discurso político insurgente asume entonces un sentido de refundación radical desconocido en la península.

Más allá de contenido de ideas, se impone, en los hechos, una cierta lógica jacobina. La idea revolucionaria se convertiría en algo más que una doctrina política: se volvería el mito fundacional de la nueva entidad que entonces emerge. La revolución se colocaría de ese modo en el lugar de aquel pasado con el que se querría cortar tan brutalmente. Pero éste es también el punto en el que toda esa forma de discursividad política encuentra aquello que constituye su límite último, aquello que resulta necesario postular pero, al mismo tiempo, se revela impensable dentro de sus marcos: cómo la nación puede representarse y constituirse a sí misma.

En efecto, como vimos, todo el discurso emancipador se sostiene en la oposición entre una nación natural, a la que se supone como preexistente, y un poder al que se postula como artificial. Quebrada esa antinomia, perdido ese sustento de un fundamento natural, resultando tanto uno como otro (la nación y el poder político) de arreglos puramente convencionales, el propio discurso revolucionario se verá enfrentado a una serie de aporías insolubles dentro de sus marcos. Esto se expresa en la paradoja contenida en el propio concepto de un congreso constituyente, el cual debe presuponer, [se repiten los adverbios terminados en "mente"] la existencia de aquello que viene, precisamente, a constituir. En efecto, todo congreso constituyente comienza proclamando ser la representación de la nación, puesto que es ella la que les ha conferido a los diputados su mandato, siendo de ella que deriva, así, la 
autoridad del congreso. Ahora bien, si de hecho fuera así, dicho congreso carecería de objeto. En definitiva, éste debe afirmar y negar sus mismos presupuestos.

En todo caso, la función de ese congreso constituyente se reduciría a constituir el Estado, pero la idea de que hubiera que "constituir la nación" o, más precisamente, la problemática de cómo es que la nación puede constituirse a sí misma, permanecerá como algo inabordable. Llegado a este punto, todo el discurso político deberá reconfigurarse sobre otras bases ya alejadas de los marcos del concepto pactista. Entramos, entonces sí, en lo que Koselleck Ilamara Sattelzeit. El concepto de Historia vendrá entonces a llenar esa laguna en el modelo pactista, aportará una respuesta a aquello que dicho modelo presuponía sin nunca poder alcanzar a responder: cómo es que se constituye el propio poder constituyente. La conformación de ese sujeto (la nación) ya no será un acto subjetivo, el resultado de una acción política, sino que se lo confiará a la propia Historia. La nación aparecerá así como el producto de un largo proceso evolutivo objetivo que opera a espaldas de los propios sujetos. Ello marcará, en fin, el tránsito hacia otro momento ya muy distinto en la historia político-conceptual.

\section{Conclusión: Hacia una nueva historia político- conceptual de las revoluciones de independencia}

La reconstrucción que realiza Halperin Donghi, según vimos, se aparta ya del tópico de los orígenes ideológicos de las revoluciones de independencia. Como señala dicho autor, tal tópico impide la comprensión de procesos ideológicos complejos. En última instancia, no habría forma de determinar si la idea pactista a la que los revolucionarios apelaron tenía raíces neoescolásticas o ilustradas. Aún más grave, sin embargo, es que, en caso de poder hacerlo, ello igualmente sería del todo irrelevante para comprender cuál fue el marco conceptual dentro del cual se inscribió el proceso revolucionario. En fin, no nos ayuda a entender, más allá de cuál es la procedencia de las ideas, qué hicieron los insurgentes con ellas y, en definitiva, 
cómo fue posible para aquellos concebir la idea misma de su autodeterminación.

El foco de la obra de Halperin Donghi ya no se colocará, pues, en las ideas o los modelos de pensamiento, sino en tratar de reconstruir un proceso ideológico, esto es, cómo se reconfiguró sucesivamente el campo discursivo; las alteraciones producidas en el plano de las condiciones de posibilidad de las ideas. Y esto tiene implícito un supuesto que lleva a ese autor a apartarse aún más tajantemente de la tradición de historia de ideas, puesto que quiebra con los marcos dentro de los que toda esa tradición se inscribe.

Esos desplazamientos o torsiones de orden simbólico que aquí se analizan son, no obstante, de naturaleza objetiva, independientes de la conciencia o la voluntad de los sujetos. No se relacionan con las ideas de los sujetos, que son atributos subjetivos, sino con el tipo de problemas frente a los cuales en cada momento los sujetos se ven confrontados (por ejemplo, cómo constituir la nación), los cuales son de naturaleza objetiva. Esto no es algo por lo que los sujetos puedan optar a voluntad, como sí pueden cambiar sus ideas y volverse, por ejemplo, más liberales o más conservadores.

Por tomar un ejemplo, el desprendimiento de la nación de la figura real no es algo que alguien haya imaginado o propuesto y que, luego, se haya difundido en la sociedad, como la historia de ideas imagina que ocurren los cambios conceptuales. Su origen no se sitúa en la mente de algún autor a quien se le hubiese eventualmente ocurrido "¿por qué no pensar la nación como algo separado del Estado?". Se trató de un fenómeno que se produjo en la propia realidad y que indicaría, a su vez, una alteración en los regímenes de ejercicio del poder (lo cual alteraría, objetivamente, las coordenadas en función de las cuales se articularía el debate político).

Encontramos aquí la reformulación fundamental que aporta este texto de Halperin Donghi. Su análisis nos remite a un plano de realidad simbólica que no circula en la mente de los 
sujetos sino que se encuentra inscripto en los propios sistemas de prácticas políticas. De ese modo, quiebra ya el supuesto de base sobre el que se funda toda la historia de ideas: la oposición entre "ideas" y "realidades" (es decir, el supuesto de que lo simbólico es algo que se coloca del lado del sujeto, algo que circula exclusivamente en la mente de los sujetos, mientras que las prácticas políticas y sociales serían realidades objetivas, crudamente materiales, desprovistas de toda dimensión simbólica). En definitiva, el apartamiento del tópico de los orígenes ideológicos de la independencia que produce Halperin Donghi conllevó una redefinición radical de su objeto, su reorientación del plano de las ideas al de la dimensión conceptual incorporada en las propias prácticas políticas y sociales, quebrando la premisa de base, de orden epistemológico, sobre la que se funda toda la historia de ideas. De ese modo, tal autor nos abre un horizonte nuevo y aún inexplorado; en fin, nos brinda un modelo para lo que podemos llamar una historia político-conceptual de las revoluciones de independencia.

\section{REFERENCIAS BIBLIOGRÁFICAS}

ARGÜELLES, Agustín. La reforma constitucional de Cádiz. Madrid: ITER, 1970.

ARTOLA, Miguel. Los orígenes de la España contemporánea. Madrid: Instituto de Estudios Políticos, 1959.

DEVOTO, Fernando. Para una reflexión sobre Tulio Halperín Donghi y sus mundos. Prismas, Revista de historia intelectual, n. 19, pp. 11-34, 2015.

FERNÁNDEZ MARTÍN, Manuel. Derecho parlamentario español. Madrid: Impr. de Hijos de J. A. García, t. I, 1885.

FURLONG, Guillermo. Nacimiento y desarrollo de la filosofía en el Río de la Plata 1536-1810. Buenos Aires: 
Guillermo Kraft, 1952.

GUERRA, François-Xavier. Modernidad e independencias. Ensayos sobre las revoluciones hispánicas. México: MAPFRE / F.C.E, 1992.

HALPERÍN DONGHI, Tulio, Tradición política española e ideología revolucionaria de Mayo, Buenos Aires: Prometeo Libros, 2010 [1ra. ed., Buenos Aires: Eudeba, 1961].

El pensamiento de Echeverría. Buenos Aires:

Sudamericana, 1951.

MARTÍNEZ MARINA, Francisco. Discurso sobre el origen de la monarquía y sobre la naturaleza del gobierno español. Madrid: Centro de Estudios Constitucionales, 1988.

SUÁREZ, Francisco. De Legibus I: De natura legis. Madrid: CSIC, 1971.

\section{AGRADECIMENTOS E INFORMAÇŌES}

Elías J. Palti

eliaspalti@gmail.com

Phd. in History.

UBA / UNQ / CONICET

Santos Dumont 23551 A, (1426) CABA,

Argentina 